\title{
Traducción chino-español de los culturemas de El rábano transparente
}

\section{Chinese-Spanish translation of the culturemes in Radish}

\author{
XIAOMENG SUN \\ 445063157@qq.com \\ Universidad de Granada
}

Fecha de recepción: 2 de junio de 2019

Fecha de aceptación: 20 de febrero de 2020

Resumen: El presente trabajo expone los resultados obtenidos en una investigación sobre la traducción castellana de los culturemas en el cuento El rábano transparente del escritor chino Mo Yan. Primero hicimos una categorización de los culturemas en el texto original, luego ejemplificamos y analizamos las técnicas de traducción que el traductor utilizó para esos culturemas. Acudiendo a métodos cuantitativos, analizamos también el grado de conservación del sentido cultural en el texto meta y la tendencia del traductor hacia la domesticación y la extranjerización. Llegamos a las siguientes conclusiones: 1) Las variadas técnicas de traducción usadas por el traductor suponen un notable equilibrio entre la domesticación y la extranjerización, sugiriendo el esfuerzo que hizo el traductor por acomodar el texto meta a sus receptores sin sacrificar el ambiente exótico del texto original. 2) Se conserva en la mayoría de los casos la connotación cultural de los culturemas, demostrando el intento del traductor de contribuir al conocimiento de los elementos propios de la cultura china por parte de los hispanohablantes. 3) Los errores de traducción que aparecen en el texto meta se deben no sólo a la mala descodificación lingüística, sino también a las desviaciones en las operaciones cognitivas, y a la falta de apoyo por parte de la editorial. Con conocimientos más sólidos sobre el contexto sociocultural en el que se desarrolla la historia original, la traducción saldría más precisa.

Palabras clave: Mo Yan, Culturema, Traducción, Chino, Español

Abstract: This article presents the results of a research on the Spanish translation of the culturemes in Radish written by the Chinese writer Mo Yan. First we categorized the culturemes in the original text. Then we exemplified and analyzed the translation techniques that the translator used for those culturemes. By employing quantitative methods, we carefully analyzed the extent of preservation of the cultural connotation in the target text and the translator's tendency towards domestication and foreignization. We have got

Hikma 19 (1) (2020), 95 - 115 
the following results: 1) The various techniques of translation used by the translator manifest a notable balance between domestication and foreignization, suggesting the effort of the translator to accommodate the target text to its receptors without sacrificing the exotic environment of the original text. 2) In most cases, the cultural connotation is preserved, demonstrating the translator's attempt to contribute to the introduction of the typical Chinese cultural elements to the Spanish speakers. 3) The errors of translation in the translated text are not only due to those false linguistic decodifications and those deviations in the cognitive operation, but also due to the lack of support of the editorial. With better knowledge of the sociocultural context in which the original story is developed, the translation would be more precise.

Key words: Mo Yan, Cultureme, Translation, Chinese, Spanish

\section{INTRODUCCIÓN}

El tema de este artículo se centrará la traducción española de los culturemas en el cuento Touming de hongluobo 透明的红萝卜 (El rábano transparente) del escritor chino Mo Yan 莫言. Los culturemas han sido uno de los enfoques en el campo de las investigaciones de traducción. Sobre el tema de traducción de culturemas y de campos afines en la combinación chino-español, han surgido múltiples investigaciones, por ejemplo: la tesis doctoral de Ku (2006) La traducción de los elementos lingüísticos culturales (chino-español). Estudio de 紅 樓夢 [Sueño en las estancias rojas]; el artículo de Cai (2015) La traducción del eufemismo del chino al español: Hongloumeng y su traducción Sueño en el Pabellón Rojo; la tesis doctoral de Yu (2016) Aproximaciones estratégicas a la traducción de los culturemas chino-español en el subtitulado televisivo. Sin embargo, existen aún muy pocas investigaciones sobre este tema en cuanto a las obras del escritor Mo Yan y, por lo tanto, quisiéramos aportar nuevas perspectivas para empezar a llenar este vacío.

El objetivo principal que se plantea en este artículo es analizar la traducción de los culturemas en este cuento de Mo Yan. Hemos desglosado este objetivo principal en dos más específicos:

1) Clasificar los culturemas que aparecen en el texto original.

2) Determinar el grado de conservación de los culturemas en el texto de llegada y analizar la tendencia del traductor hacia una traducción domesticante o extranjerizante. 
La investigación que nos proponemos realizar es esencialmente descriptiva. Para este análisis traductológico partiremos de la categorización de los culturemas y de las técnicas de traducción propuestas por Molina (2006). Empezaremos con una introducción breve sobre el cuento que nos sirve de objeto de investigación. A continuación, repasaremos las teorías más destacadas relacionadas con el tema del culturema, y posteriormente iniciaremos el análisis de los datos encontrados, que a su vez contendrá dos partes: el análisis de los culturemas aparecidos en el texto original chino y el de la traducción de ellos. El análisis de los culturemas se llevará a cabo a base de los datos recogidos en el texto original y el texto meta, en los que abarcan informaciones como la formulación original y la traducida del culturema, su tendencia a la domesticación o a la extranjerización, y el grado de conservación de la connotación cultural (véase en el anexo un ejemplo de las fichas recogidas en los textos).

En concreto, realizaremos un análisis cuantitativo y cualitativo de los 81 culturemas junto con sus traducciones en castellano que hemos encontrado en el TO y el TM. Entre ellos, no hemos contado las repeticiones (por ejemplo, si aparece tres veces la palabra li 里 como una medida, sólo contamos una). Cabe destacar que, en los análisis de las técnicas de traducción, en algunos casos, la suma de las fichas que utilizaremos en las tablas no coincide con esta suma de 81 porque a veces el traductor emplea, por ejemplo, más de una técnica de traducción para una palabra china (por ejemplo, en la traducción de cunzhuang 村庄, «la aldea-el cun», el traductor combina dos técnicas), o simplemente porque en cierta ficha el traductor comete un error en la traducción que no implique ninguna técnica.

\section{JUSTIFICACIÓN DE LA OBRA}

Touming de hongluobo, publicado en el año 1985, es uno de los cuentos más representativos de Mo Yan. Nació en el año 1955 en una familia campesina de un pueblo llamado Gaomi 高密, de la provincia de Shandong 山东, que luego se convertiría en el escenario de muchas de sus novelas. Vivió la gran hambruna (1959-1961) que arrasó todo el país cuando apenas tenía seis años, hecho que le dejó profunda influencia en la creación literaria. Fue también testigo de la Revolución Cultural (1966-1976), uno de los disturbios políticos y sociales más graves que acontecieron después de la fundación de la República Popular China. En los años 80 empezó a escribir cuentos y novelas, entre los cuales destaca el que analizamos en este

artículo, Touming de hongluobo, y Honggaoliang 红高粱 (Sorgo rojo), Tiantang suantai zhige 天堂赫臺之歌 (Las baladas del ajo), Shengsi pilao 生 
死疲劳 (La vida y la muerte me están desgastando), Wa 蛙 (Rana), entre otros. En el año 2012, recibió el Premio Nobel de Literatura.

Este cuento que servirá como objeto de nuestro análisis cuenta la historia de un niño de unos diez años en la época de la Revolución Cultural, cuando trabajaba como ayudante en una obra pública para agrandar la compuerta hidráulica. Este niño, Heihai 黑孩 (traducción literal: niño negro; traducción en la versión castellana: Tizón), maltratado por su madrastra, era extremadamente flaco y callado, pero tenía una sensibilidad sorprendente hacia el mundo natural: la luz, los olores, los colores, los sonidos, etc. Una noche creyó que vio un rábano dorado, que en los ojos de ese niño hambriento era algo increíblemente bonito. Sin embargo, ese rábano fue tirado maliciosamente por el herrero al que ayudaba, y así empezó a buscar ese rábano, arrancando del campo de cultivo al final numerosos rábanos todavía no maduros, hecho por lo cual recibiría castigo. Este cuento describe, mediante los comportamientos de los trabajadores en aquella obra pública, el panorama de las zonas rurales durante aquel periodo de grandes disturbios: la pobreza, el hambre, la bondad y la maldad.

Las obras de Mo Yan han sido traducidas a múltiples lenguas extranjeras incluyendo el inglés, el francés y el italiano. En el mundo hispánico, es uno de los escritores chinos más traducidos, con 14 libros publicados en España (no hemos contado las re-traducciones ni reimpresiones). La versión castellana llamada El rábano transparente fue publicada en el año 2017, traducida por Blas Piñero Martínez directamente de la versión original en chino. Hasta ahora es la única versión traducida al español. Este traductor empezó su carrera como traductor de la literatura china desde el año 2011, con la publicación de la novela El camello Xiangzi de Lao She 老舍. Ante de publicar la traducción de El rábano transparente, tradujo ya tres novelas de Mo Yan: El suplicio del aroma de sándalo (2014), El manglar (2016), y El clan del sorgo rojo (2016). También tradujo dos antologías de la poesía moderna china. Es uno de los traductores con más experiencias en la traducción de la literatura moderna y contemporánea china, en especial en la traducción del escritor Mo Yan.

Hemos escogido este cuento como material de análisis porque en el sentido cuantitativo, como historia típica de aquella época, cuenta con numerosos culturemas y la mayoría de ellos son muy importantes cuando los destinatarios, tanto del texto original como del texto meta, intentan percibir el mensaje que transmite los textos. Debido a la gran diferencia entre el contexto situacional y sociocultural original y el contexto meta, estos culturemas resultan en especial novedosos e incluso difíciles de comprender para esos receptores del texto meta, y las intervenciones traductoras determinan en 
gran medida la calidad de ese proceso comunicativo entre el emisor del texto original y el destinatario del texto meta.

\section{LOS CULTUREMAS: BREVE INTRODUCCIÓN TEÓRICA}

El «culturema», también llamado «elemento cultural», «ámbito cultural», etc., es un concepto propuesto por numerosos teóricos en el campo de la traductología. Nida (1945) empezó a distinguir entre cinco «ámbitos culturales»: ecología, cultural material, cultura social, cultural religiosa y cultura lingüística. A estas divisiones Newmark (1988, p. 95) les añadió los elementos paraverbales como los gestos y hábitos, y denominó a este tipo de elementos «palabras culturales» o «categorías culturales». El término «culturema» fue propuesto por Vermeer en 1983 (cfr. Nord, 1997, p.34), y sus definiciones fueron enriquecidas posteriormente por teóricos como Nord (1997, p.34), Molina (2006, p. 79-82), Luque Nadal (2009), etc.

Molina (2006, p. 79) define el culturema como «un elemento verbal o paraverbal que posee una carga cultural específica en una cultura y que al entrar en contacto con otra cultura a través de la traducción puede provocar un problema de índole cultural entre los textos origen y meta». Esta misma teórica (Molina, 2006, pp. 79-82) propone también una clasificación concisa y accesible para los culturemas:

1) Medio natural: ecología (flora, fauna, fenómenos atmosféricos, vientos, climas, etc.), ambiente natural (paisajes naturales y creados por el ser humano) y los topónimos.

2) Patrimonio cultural: a) historia, cultura religiosa y folklore; b) cultura material.

3) Cultura social: a) convenciones y hábitos sociales; b) organización social.

4) Cultura lingüística: la fonología y el léxico.

Utilizaremos en este artículo la definición y clasificación de Molina por los siguientes motivos:

1) La clasificación de los culturemas de cuatro categorías es más concisa en comparación con las clasificaciones de otros traductólogos como Nida y Newmark, y resultará más accesible para el análisis;

2) Tiene un punto de vista dinámico hacia los culturemas, opinando que ellos «no existen fuera de contexto» ni pueden ser encontrados en una sola cultura, sino que siempre surgen en una 
«transferencia cultural» entre dos culturas concretas (Molina, 2006, p. 78).

Como estos culturemas son muy característicos en una cultura específica, pueden resultar desconocidos en las otras. De esta manera se convierten en un obstáculo en el proceso de traducción, que casi siempre se basa en los conocimientos compartidos por la cultura de partida y la de llegada. Especificó (Molina, 2006, pp. 101-104) unas técnicas que podrían ser utilizadas en la traducción de culturemas: 1) adaptación; 2) ampliación lingüística; 3) amplificación; 4) calco; 5) compensación, 6) comprensión lingüística 7) creación discursiva 8) descripción; 9) equivalente acuñado; 10) generalización; 11) modulación; 12) particularización; 13) préstamo; 14) reducción; 15) substitución; 16) traducción literal; 17) transposición; 18) variación.

\section{ANÁLISIS DE LOS RESULTADOS OBTENIDOS}

En este apartado llevaremos a cabo un análisis cuantitativo de los 81 culturemas que hemos encontrado después de haber comparado el texto original (TO) y el texto meta (TM).

\subsection{Culturemas en el texto original: una clasificación}

Según la clasificación arriba citada, encontramos en el cuento culturemas de las cuatro categorías, aunque el porcentaje que ocupan los culturemas de la cultura social (45\%) y los de la cultura lingüística $(43 \%)$ es mucho más elevado, reflejando la preferencia del escritor chino de introducir una gran cantidad de refranes y expresiones vulgares en este cuento. Muestra, al mismo tiempo, lo arraigado que está este cuento en la realidad social y política de aquella época. Pasamos a ejemplificar cada categoría para dar a conocer nuestro ámbito de investigación.

Las tres fichas pertenecientes a la categoría del medio natural son todos topónimos. Por ejemplo:

Ejemplo 1. Medio natural.

$$
\text { 亲㸘鬼迷心空下了关东, 一去三年没个影。(Mo Yan, 2012, p. 4) }
$$

Su padre fue enviado a las regiones del noreste y hace más de tres años que no se le ha visto ni la sombra. (Mo Yan, 2017, p. 19)

La palabra Guandong 关东 (traducción literal: el Este del Paso) se refiere a la zona fría y desierta al norte y este del Shanhaiguan 山海关 (traducción literal: Paso de Shanhai), cuando numerosas personas del centro 
de China, entre los siglos XVII y XIX, se trasladaron allí en busca de fortuna. El traductor emplea la técnica de descripción, explicando directamente la zona a la que se refiere esta palabra.

Los culturemas sobre el patrimonio cultural abarcan múltiples temas como, por ejemplo, la historia, la arquitectura y la literatura. Introducimos un ejemplo:

Ejemplo 2. Patrimonio cultural.

你全不念三载共枕, 如云如雨。(Mo Yan, 2012, p. 31)

Tres años ya que me has tenido junto a ti, y con las nubes y la lluvia. (Mo Yan, 2017, p. 75)

Yunyu 云雨 (traducción literal: nubes y lluvias) simboliza la relación sexual entre hombre y mujer. Su origen se remonta a una frase de Gaotangfu 高唐赋 (Prosa rimada de Gaotang) de Song Yu 宋玉: 《旦为朝云, 暮为行雨, 朝 朝暮暮，阳台之下 (traducción literal: por la mañana me convierto en nubes, por la tarde en lluvias, y todos los días estoy bajo la Montaña Yangtai)» (Jiang, 1983, p. 149). El traductor elige una traducción literal sin añadir ni explicaciones ni notas, hecho que puede dificultar la comprensión a los receptores de la lengua meta porque se trata de una expresión eufemística muy típica de la cultura original.

Los culturemas del ámbito de cultura social son numerosos. El ejemplo que aquí proponemos es un reflejo de la situación social y política de aquellos años de la Revolución Cultural:

Ejemplo 3. Cultura social.

黑孩家三代贫农，社会主义不管他谁管他？(Mo Yan, 2012, p. 4)

Tizón pertenece a una familia campesina de tres generaciones muy pobres... ¿Y no va el socialismo a hacerse cargo de él? (Mo Yan, 2017, p. 19)

La palabra pinnong 贫农 (traducción literal: campesino pobre) pertenece al sistema de clases sociales después de la fundación de la República Popular de China en el año 1949. Los más pobres que no tenían tierra o los que tenían muy poca fueron la clase social más valorada según las políticas del gobierno, por lo cual aquí el mampostero se lo recordó al jefe de la comuna para que ayudara al niño Tizón. El traductor la tradujo literalmente, conservando todo el sentido cultural.

Los culturemas de la cultura lingüística también son muy representados en el cuento. Abarcan, por ejemplo, insultos (como por 
ejemplo, gouniang yangde 狗娘养的, traducción literal: criado por una perra), asociaciones simbólicas típicas de la cultura original (como por ejemplo, maotouying 猫头鹰, traducción literal: lechuza), y refranes:

Ejemplo 4. Cultura lingüística.

\section{狗息子，狗咬吕洞宾，不识好人心。(Mo Yan, 2012, p. 17)}

Eres un perrito, como el perro que mordió al bueno de Lü Dongbin... No conoces la voluntad del pueblo.

Nota del traductor: Lü Dongbin, que nació en el año 796, era uno de los componentes del grupo de los Ocho Inmortales del panteón taoísta. (Mo Yan, 2017, p. 48)

El traductor acude a la técnica de amplificación, añadiendo primero la palabra «bueno» para describir a Lü Dongbin, y luego una nota explicando la identidad de ese personaje. En lugar de señalar el sentido de la frase- que uno no podía distinguir lo bueno de lo malo y le echaba la culpa a una persona buena (Xu \& Ying, 2004, p. 304)-, conservó por completo la connotación cultural.

\subsection{La traducción de los culturemas en el texto de llegada}

Nuestro enfoque de esta parte se sitúa en las técnicas que el traductor utiliza en la traducción de los culturemas, el grado de conservación (conservación completa, parcial o pérdida) y su tendencia hacia la domesticación o la extranjerización.

\subsubsection{Técnicas empleadas en la traducción de los culturemas}

En total se han empleado nueve técnicas en la traducción de los culturemas, y en algunos casos se nota la omisión por completo de cierto culturema. La frecuencia con la cual se utilizan estas técnicas y la omisión se muestra en la siguiente tabla:

\begin{tabular}{|l|l|}
\hline Técnicas de traducción & Porcentaje \\
\hline Traducción literal & $18 \%$ \\
\hline Equivalente acuñado & $18 \%$ \\
\hline Generalización & $15 \%$ \\
\hline Préstamo & $13 \%$ \\
\hline Amplificación & $12 \%$ \\
\hline Omisión & $9 \%$ \\
\hline
\end{tabular}

Hikma 19 (1) (2020), 95 - 115 


\begin{tabular}{|l|l|}
\hline Adaptación & $9 \%$ \\
\hline Descripción & $6 \%$ \\
\hline Transposición & $3 \%$ \\
\hline Particularización & $1 \%$ \\
\hline
\end{tabular}

Tabla 1: Técnicas de traducción

Siguiendo este orden de frecuencia, exponemos diez casos representativos para ejemplificar la utilización de estas técnicas de traducción. Debido al amplio uso de la omisión, en el TM, aquí también incluimos un ejemplo para este caso.

1) Traducción literal

Ejemplo 5. Cultura lingüística.

后娘一怕天打雷, 二怕猫头鹰叫。(Mo Yan, 2012, p. 28)

La madrastra temía como pocas cosas en este mundo los truenos del cielo y los gritos de los mochuelos. (Mo Yan, 2017, p. 70)

En la cultura occidental el mochuelo simboliza sabiduría, pero en la china simboliza la muerte, así que no es de extrañar que la madrastra les tuviera miedo. Además, existen cuentos folklóricos chinos que dicen que el trueno castiga a las personas que han hecho cosas muy malas, y aquí el temor al trueno podría insinuar que ella misma temía que podría ser castigada por el maltrato que había hecho a Tizón. El empleo de la técnica de traducción literal conserva íntegramente la formulación del culturema, pero el traductor corre el riesgo de causar confusiones entre sus receptores españoles debido a la interferencia cultural: ¿por qué uno tiene miedo al mochuelo?

\section{2) Equivalente acuñado}

Ejemplo 6. Cultura lingüística.

你们村真他妈的会找人, 派你这个笑篱捞不住的滑蛋来, 够我淘的 啦。(Mo Yan, 2012, p. 4)

La madre que parió a vuestra aldea y a su gente... ¿Quién es el huevón que os ha enviado? Ese ya me ha tocado suficientemente las narices...

(Mo Yan, 2017, p. 19)

3) Generalización

Ejemplo 7. Cultura social. 
桥洞里很暗, 他摸摸索索地坐在老铁匠的马扎上。(Mo Yan, 2012, p. 19)

El agujero del puente estaba muy oscuro y, temblando, el niño se sentó sobre un taburete junto al herrero viejo. (Mo Yan, 2017, p. 51)

Mazha 马扎 (mǎzhā) es un tipo de asiento pequeño, con las piernas cruzadas, y por encima se añade tela o cuerdas. Se puede plegar para que sea portátil (Zhongguo shehui kexueyuan yuyan yanjiusuo cidian bianjishi, $2005,909)$. Taburete, en cambio, es «un asiento sin brazos ni respaldo, para una persona» (Real Academia Española, 2019). Es decir, 马扎 siempre se hace con tela o cuerda y se puede doblar, pero la palabra «taburete» tiene un sentido más amplio.

4) Amplificación

Ejemplo 8. Cultura lingüística.

\section{我寻思着你该去见阎王了。(Mo Yan, 2012, p. 2)}

Pensé que ya te habías ido a visitar al rey Yan, el rey de los infiernos... (Mo Yan, 2017, p. 13)

La frase significa, de manera eufemística y humorística, morir, porque el rey Yan era el encargado del mundo de los muertos. El traductor conserva este sentido cultural traduciendo literalmente Yanwang 阎王 como «el rey Yan», añadiendo la explicación «el rey de los infiernos» para que los receptores capturen correctamente el significado. En el Ejemplo 4, el traductor también acude a la combinación de una traducción literal y una explicación (nota del traductor) que aclara la identidad del personaje histórico Lü Dongbin. A nuestro juicio, esa combinación es útil y necesaria porque conserva el sentido cultural sin interrumpir la lectura de los receptores.

5) Préstamo

Ejemplo 9. Patrimonio cultural.

老老少少的人从胡同里涌出来, 汇集到钟下。(Mo Yan, 2012, p. 1)

Tanto los viejos como los jóvenes salieron de los hutong y se reunieron bajo la campana. (Mo Yan, 2017, p. 11)

Hutong 胡同 es una calle estrecha o callejón, muy típica en el norte de China. Se trata de un préstamo naturalizado, usando la pronunciación del chino, pero transcribiendo la palabra con letras latinas en cursiva.

6) Omisión

Ejemplo 10. Patrimonio cultural.

Hikma 19 (1) (2020), 95 - 115 
黑孩起初还以那双大眼睛的偶然一瞥来回答姑娘的关注, 但很快就 像入了定一样, 眼睛大睁着, 也不知他看着什么... (Mo Yan, 2012, p. 10)

Tizón no podía al principio retirar sus ojos de la joven, pero no tardó en apartarlos, algo avergonzado, y se puso a mirar a otra parte, sin saber en realidad a dónde, con sus ojos bien abiertos. (Mo Yan, 2017, p. 31)

Ruleding 入了定 significa entrar en estado de meditación chanding 禅 定. Se trata de una práctica del Budismo para aumentar la comprensión y la sabiduría, y como los practicantes tenían que estar, durante un largo período de tiempo, muy tranquilos, esta frase sirve también como una metáfora para describir el estado muy ensimismado de una persona. El traductor omite por completo esta frase.

7) Adaptación

Ejemplo 11. Cultura lingüística.

这孩子可灵性哩, 他四五岁时说起话来就像竹筒里晃踠豆, 咯嘣咯 嘣脆。(Mo, 2012, p. 12)

Lo que tenía era una naturaleza espiritual y era un niño muy despierto e inteligente. Hablaba desde los cuatro o cinco años y hablaba por los codos. (Mo, 2017, p. 36)

Según Seco (2009, p. 291), hablar por los codos es un refrán en español que significa hablar de manera exagerada. El traductor quita la metáfora de zhutong li huangwandou 竹筒里晃踠豆 (traducción literal: sacudir los guisantes en un tubo) para emplear un refrán bien conocido en español, hecho que conduce a la pérdida del sentido cultural original.

8) Descripción

Ejemplo 12. Cultura social.

黑孩的脚上穿着一双崭新的回力球鞋, 由于鞋子太大, 只好紧紧地 系住鞋带。(Mo Yan, 2012, p. 45)

También calzaba unas zapatillas de deporte resistentes, pero que eran demasiado grandes. Por eso debía atar los cordones varias veces y con mucha fuerza. (Mo Yan, 2017, p. 108)

Huili 回力 es una marca de zapatillas de deporte muy conocida en China. Desde los años 40 ya se hizo popular y sus productos se caracterizaban por la resistencia. En aquella época, en la que se desarrolla este cuento, tener unas zapatillas nuevas de esta marca era casi un lujo. En 
lugar de intentar conservar la formulación original, el traductor sólo describe la característica más importante de este tipo de zapatillas, omitiendo por completo el nombre de la marca.

9) Transposición

Ejemplo 13. Cultura social.

社会主义优越性嘛, 人人都要吃饭。(Mo Yan, 2012, p. 4)

El socialismo es superior a otros regímenes políticos... A nadie le falta nada para comer en este país... (Mo Yan, 2017, p. 19)

Esta frase shehuizhuyi youyuexing 社会主义优越性 era uno de los eslóganes propagandísticos más populares de aquella época, que significa literalmente la superioridad del socialismo. Utilizando la técnica de transposición, el traductor cambió esa frase nominal a una oración con un sujeto "el socialismo» y un verbo «es» para añadir "otros regímenes políticos», con el fin de que observe mejor las costumbres de expresión del español y que los lectores que no estén familiarizados con el contexto social la puedan entender con facilidad.

10) Particularización

Ejemplo 14. Cultura social.

地瓜地的北边是一片菜园, 社员的自留地统统归了公。(Mo Yan, 2012, p. 5)

Al norte del campo de batatas había un huerto que se gestionaba originalmente en privado, pero que los miembros de la comuna lo hicieron público. (Mo Yan, 2017, p. 22)

La palabra ziliudi 自留地 (traducción literal: tierra reservada para sí mismo) no se refiere necesariamente al huerto, sino a todo tipo de tierra que podía reservar cada familia para cultivar lo que le pareciera necesario. De acuerdo con el contexto, el traductor acude a una traducción más específica.

Entre todas las técnicas arriba mencionadas, las dos que más se usan en esta versión traducida son la de equivalente acuñado y la de traducción literal. Con la primera el traductor intenta buscar un término o una expresión ya reconocida en la lengua meta, el castellano, para que sea el equivalente de los términos de la lengua original. Siendo una técnica domesticante, contribuye a una pérdida parcial e incluso completa de la connotación cultural que conllevan los culturemas en la cultura original. Mediante la segunda técnica, se conserva la formulación original y el sentido cultural, pero se dificultará la lectura de los receptores del texto meta, porque a veces estos términos o frases en dicho texto suelen carecer de significado. Eso sucede,

Hikma 19 (1) (2020), 95 - 115 
según los datos recogidos, con mayor frecuencia cuando el traductor elige reproducir literalmente los insultos y blasfemias. Por ejemplo:

Ejemplo 15. Cultura lingüística

等着吧, Y头养的你们! (Mo Yan, 2012, p. 38)

A vosotros os ha criado una yatou. (Mo Yan, 2017, p. 91)

En este ejemplo, el traductor combina dos técnicas: préstamo (al traducir la palabra Y头 con una transliteración yatou) y traducción literal (al traducir el verbo 养 con el verbo criar). Sin conocimientos profundos sobre el chino, a los lectores del mundo hispánico les resultará imposible entender de qué se trata un $Y$ 头 (traducción literal: sirvienta) al ver el préstamo "yatou», y eso les impide capturar el sentido ofensivo. En este caso, nos parece adecuado y necesario acudir a la técnica de amplificación, donde el traductor añade una explicación a cierto término o frase que resultarán extraños para los receptores, sea dentro del texto, o en las notas del traductor. Debido a la lejanía que existe entre las dos culturas, se aprecia el intento de combinar la técnica de traducción literal y la de amplificación, porque de esta manera se puede facilitar el entendimiento de los receptores sin sacrificar los elementos característicos de la cultura china.

\subsubsection{Grado de conservación de los culturemas en la traducción}

El otro factor que queremos tener en cuenta cuando realizamos los análisis es el grado de conservación de la formulación original y el sentido cultural del culturema. Dividimos en tres grupos todas las fichas recogidas:

\section{Grado de conservación del sentido cultural}

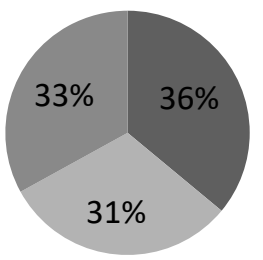

- Conservación completa

Conservación parcial

Pérdida

Figura 1: Grado de conservación del sentido cultural de los culturemas

Hikma 19 (1) (2020), 95 - 115 
1) Conservación completa. En este caso, se conserva íntegramente la formulación del culturema original. Las técnicas que suelen conducir a una conservación completa son la traducción literal, la amplificación y el préstamo. En esta circunstancia, el traductor intenta acercarse al extremo de la cultura original, presentando en la medida de lo posible los elementos chinos. Un ejemplo que ilustra bien esta conservación es la traducción de las medidas tradicionales de China ( $l i$ 里, jin 斤, $m u$ 亩), y la única técnica que el traductor utiliza es el préstamo.

Ejemplo 16. Cultura social.

黑孩, 你离家几里? (Mo Yan, 2012, p. 11)

-Tizón, ¿a cuántos li está tu casa de aquí? (Mo Yan, 2017, p. 32)

Ejemplo 17. Cultura social.

你骏马高官, 良田万亩。(Mo Yan, 2012, p. 31)

Tú, letrado y alto oficial del imperio, cabalgas ahora sobre tu corcel sobre la tierra fértil de diez mil mu. (Mo, 2017, p. 75)

En el ejemplo 16, el traductor usa la pronunciación del chino, transcribiendo la palabra li 里 con pinyin, el sistema de romanización del chino. Lo mismo ocurre con la medida 亩 en el ejemplo 17, cuya traducción es simplemente mu. Sin lugar a dudas, la introducción de esas medidas extranjeras le da un ambiente bien exótico al cuento, y como marca todas esas palabras de origen chino en cursiva, será posible que los receptores del TM deduzcan, según el contexto, el significado de ellas aunque no sepan nada sobre el sistema de medidas tradicionales de China.

2) Conservación parcial. En este caso, se conserva sólo una parte del sentido cultural del culturema. Las técnicas utilizadas son más variadas, ya que incluye generalización, descripción, adaptación, reducción, etc. El traductor intenta alcanzar un equilibrio entre las informaciones ya conocidas por los receptores y las nuevas para ellos, hecho que abrirá más posibilidades de aceptación. Por ejemplo, en la traducción «capitalista» para la palabra zouzipai 走资派, que originalmente consiste en la abreviatura de zou zibenzhuyi daolu de dangquanpai 走资本主义道路的当权派 (traducción literal: los líderes con poder que se encaminan hacia el capitalismo), conserva solamente el sentido de capitalista sin referirse a los líderes:

Ejemplo 18. Cultura social.

你他妈的在那儿干什么, 弯腰撅腚, 冒充走资派吗? (Mo Yan, 2012, p. 21) 
Pero ¿qué haces ahora ahí doblado en el agua? ¿Te crees un capitalista o qué? (Mo Yan, 2017, p. 56)

En realidad, 走资派 era el tratamiento para llamar a los líderes y oficiales de alto rango del Partido Comunista que, según el presidente Mao Zedong 毛泽东, tenían tendencias al capitalismo. Fueron criticados e insultados frente al público durante la Revolución Cultural, con posturas humillantes como estar doblado, y justamente de esa postura venía esa pregunta en el texto original. La técnica aquí utilizada, la reducción, no puede transmitir suficientemente la información del TO porque para los receptores será muy difícil comprender la relación que tiene un capitalista y un niño que está doblado sin una explicación del fondo histórico.

3) Pérdida. Se observa, ante todo, el porcentaje bastante alto de los casos en los cuales se pierden totalmente la formulación del culturema. Intentamos clasificar las razones por las cuales se ha perdido por completo la formulación y el sentido cultural del culturema:



Figura 2: Causas de las pérdidas del sentido cultural

Cabe señalar que, ante todo, en muchos casos una pérdida del sentido cultural del culturema no supone un error. En el ejemplo 11 hemos presentado un caso en el cual el traductor, utilizando la técnica de adaptación, encontró un refrán reconocido en español para traducir un refrán chino. Según la teoría de equivalencia dinámica de Nida y Taber (1986, p. 237), como esa traducción recibirá, muy posiblemente, una respuesta igual entre los receptores del TM y entre los del TO, podemos afirmar que el mensaje ha 
sido transferido con éxito y que se ha alcanzado una equivalencia. De igual manera, las omisiones, si son adecuadas, también son aceptables.

Nuestro énfasis se sitúa en el análisis de errores porque ese factor contribuye a la mayoría de las pérdidas y la corrección en este aspecto mejorará en gran medida la calidad del TM y aumentará la facilidad de aceptación entre receptores. Dancette (cfr. Hurtado, 2016, pp. 292-293) propone dos tipos de causas de las traducciones falsas: mala descodificación lingüística (mal análisis morfológico, sintáctico o semántico y desconocimiento léxico) y operaciones cognitivas erróneas, que abarca construcciones de inferencias erróneas, ausencia de conocimientos previos para captar los elementos implícitos y construcciones de presuposiciones erróneas. Se puede atribuir los errores que hemos detectado a ambas causas.

Ejemplo 19. Cultura social.

菊子，想认个干儿吗？(Mo Yan, 2012, p. 9)

Crisantemo, ¿no reconoces a ese niño? (Mo Yan, 2017, p. 30)

Ejemplo 20. Cultura lingüística.

(小男孩)看着他来了, 便扬起那张扁乎乎的脸, 彥慜着手叫: “可......可......抱......” (Mo Yan, 2012, p.2)

Ese niño, al verle venir, alzó la cabeza y dijo, haciendo un gesto con la mano: - ¿Puedes?... ¿Puedes aguantártelos?... (Mo Yan, 2017, p. 15)

En el ejemplo 19, el traductor entendía mal la palabra gan'er 干儿 (traducción literal: hijo no consanguíneo), cometiendo un error debido al desconocimiento léxico y luego al mal análisis semántico. Es una costumbre china reconocer a los hijos de los mejores amigos como 干儿 (si es un niño) o gan nüer 干女儿 (si se trata de una niña). El concepto más cercano en español es «ahijado», aunque la costumbre china carece de sentido religioso. En este caso, sin embargo, la mujer le preguntó a la chica Crisantemo si quería tener a Tizón como ahijado no porque de verdad quería saber la respuesta. Al contrario, quería reírse de esa chica por haber mostrado tanto cariño a un niño desconocido como Tizón, preguntando prácticamente si ella quería tenerle a ese niño como su futuro marido. Se aclara esa insinuación con sus siguientes frases preguntando si ella se enamorada del niño:

菊子, 是不是看上他了? 想招个小女婿吗? 那可够你獒的, 这只小 鸭子上架要得几年哩…… (Mo Yan, 2012, p. 9) 
¿No es ese el hijo de ese tipo? Ese ya te ha machacado lo suficiente... Ese patito te ha mantenido muchos años... (Mo Yan, 2017, p. 31)

Sin poder descifrar correctamente el significado de esa palabra clave, será imposible elegir una traducción adecuada para el verbo ren 认, una palabra bastante polisémica en chino.

En el ejemplo 20, el traductor entendía la palabra 可 como un verbo que significa "poder». De hecho, es un significado de uso frecuente en el chino moderno. Sin embargo, según el contexto, se deduce que la repetición keke 可可 es una palabra mal pronunciada por un niño, el hermano menor de Tizón, quien quería llamar a su hermano, a su gege 哥哥. Esa inferencia errónea no se debe a la mala descodificación lingüística, sino a una inferencia errónea que el traductor cometió en su proceso de entender el TO.

Tras este análisis de grado de conservación en el proceso de traducción, observamos que:

1) En el $67 \%$ de los culturemas se ha conservado, de forma completa o parcial, su sentido cultural en el proceso de traducción, demostrando el intento del traductor de contribuir al conocimiento de la cultura china por parte de los receptores hispánicos.

2) En cuanto a las pérdidas por completo del sentido cultural de los culturemas, más de la mitad de ellas se debe a los errores que cometió el traductor. En este caso, se recomendaría más atención por parte del traductor sobre el contexto en el que se sitúan los culturemas para alcanzar mejores resultados de traducción. Sin embargo, en el proceso complejo de la traducción, los errores de los traductores se atribuyen también a las faltas en los proyectos de traducción de las editoriales, así que son necesarios más apoyos por parte de la editorial.

\subsubsection{Tendencia a domesticación o extranjerización}

Habiendo admitido que una traducción nunca será completamente suficiente para el texto original, Venuti (1995, p. 20) propuso que un traductor podía elegir entre dos métodos de traducción. Uno sería domesticante, que es una reducción etnocéntrica del texto original para adaptarse a los valores culturales de la lengua meta, llevándole a la cultura meta al autor; y el otro sería extranjerizante, que implica una desviación de estos valores para introducir las diferencias lingüísticas y culturales del texto original, llevando a los lectores a la cultura original. 
Según los datos recogidos al respecto, observamos que el porcentaje de las traducciones domesticantes supera de madera moderada el de las extranjerizantes:

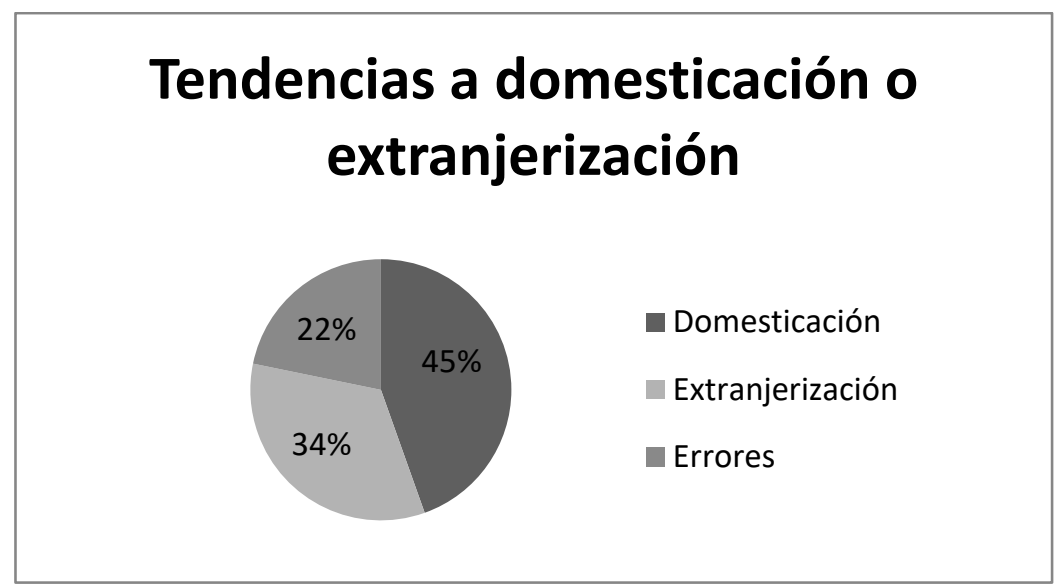

Tabla 4: Tendencia a domesticación o extranjerización

Un $45 \%$ de las fichas traducidas al español muestran tendencia a domesticación, mientras que un 34\% tienden a la extranjerización. El 22\% de ellas son errores que excluimos de ese análisis. La técnica más usada que conduce a la domesticación es equivalente acuñado, y la que contribuye a la extranjerización es traducción literal. El porcentaje similar que ocupan las dos tendencias muestra que el traductor intenta buscar un equilibrio entre el extremo del TO, procurando mantener el sentido cultural de los elementos chinos, que suponen información nueva y atractiva para sus receptores; y el extremo del TM, haciendo más accesible su traducción porque se supone que la mayoría de esos receptores no son expertos en la cultura china y que demasiados términos desconocidos dificultan su entendimiento y aceptación.

\section{CONCLUSIONES}

Desde el punto de vista comunicativo, la traducción consiste en «la reformulación de un texto con los medios de otra lengua, y siempre se desarrolla en un contexto social y con una finalidad determinada» (Hurtado, 2016, p. 41). Basándonos en los análisis anteriores y considerando la naturaleza del texto original (un cuento, una ficción), podemos señalar unos aspectos específicos en el texto original y el texto meta con respecto a los culturemas. Por consiguiente, confirmamos que: 
1) Contamos con la aparición de las cuatro categorías de culturemas, entre las cuales los culturemas de la cultura social y de la cultura lingüística ocupan un porcentaje mucho más alto que las otras dos. Se trata de un cuento con rasgos característicos muy típicos de la época de la Revolución Cultural, y el lenguaje es vívido y lleno de refranes y frases hechas populares en la zona Shandong de China. Esos culturemas en muchos casos proporcionan informaciones clave para la comprensión del texto, y aumentan la dificultad de traducción.

2) Hemos observado una variedad de técnicas empleadas en el proceso de traducción, y las dos técnicas más utilizadas son la de equivalente acuñado y la de traducción literal. Hace falta destacar que en las traducciones entre dos culturas lejanas es útil y necesaria la combinación de la técnica de traducción literal y la de amplificación, porque la primera ayuda a la conservación de la connotación cultural y la segunda facilita la comprensión. Se nota un equilibrio entre técnicas domesticantes y extranjerizantes, mostrando el intento del traductor de proporcionarles a los receptores más facilidades de aceptación y, mientras tanto, ofrecerles más oportunidades de conocer la China de aquella época especial. En este sentido, se puede calificar de exitosa esta versión de traducción.

3) En más de la mitad de los culturemas se conserva de forma parcial o completa el sentido cultural original. En caso de pérdidas por completo de la connotación cultura, tampoco se puede negar el esfuerzo que el traductor ha hecho por acercar la traducción a los receptores. Sin embargo, se observan también pérdidas de esa índole debido a los errores, que fueron causados por la mala descodificación lingüística, las operaciones cognitivas erróneas y, por supuesto, la falta de apoyo por parte de la editorial.

\section{REFERENCIAS BIBLIOGRÁFICAS}

Cai, Y. (2015). La traducción del eufemismo del chino al español: Hongloumeng y su traducción Sueño en el Pabellón Rojo. Hikma, (14), 37-54.

Hurtado, A. (2016). Traducción y traductología: introducción a la traductología. Madrid: Cátedra.

Jiang, S. 姜书阁. (1983). Xianqin cifu yuanlun 先秦辞赋原论 (Análisis de los cifu antes de la Dinastía Qin). Jinan: Qilu shushe. 
Ku, M. (2006). La traducción de los elementos lingüísticos culturales (chinoespañol). Estudio de 红楼梦 [Sueño en las estancias rojas] (Tesis doctoral). Universidad Autónoma de Barcelona, Barcelona.

Luque Nadal, L. (2009). ¿Los culturemas: unidades lingüísticas, ideológicas o culturales? Language Design, 11, 93-120.

Mo Yan. 莫言. (2012). Touming de hongluobo 透明的红萝卜 (El rábano transparente). En Huanle 欢乐 (Felicidades) (pp. 1-47). Shanghai: Shanghai wenyi chubanshe.

Mo Yan. (2015). Radish (H. Goldblatt, Trad.). Melbourne, Vic.: Penguin Books Australia.

Mo Yan. (2017). El rábano transparente (B. P. Martínez, Trad.). Madrid: Kailas.

Molina, L. (2006). El otoño del pingüino: análisis descriptivo de la traducción de los culturemas. Castellón: Universidad de Jaime I.

Newmark, P. (1988). A textbook of translation. Hertfordshire: Prentice Hall International.

Nida, E. (1945). Linguistics and Ethnology in Translation Problems. Word, (2), 194-208.

Nord, C. (1997). Translating as a purposeful activity: Functionalist approaches explained. Manchester: St. Jerome Publishing.

Nord, C. (2010). Las funciones comunicativas en el proceso de traducción: un modelo cuatrifuncional. Núcleo, 27, 239-255.

Real Academia Española. (2019, mayo 24). Taburete. Recuperado de Diccionario de la lengua española website: https://dle.rae.es/?id=Yu13yY7

Seco, M., Andrés, O., \& Ramos, G. (2009). Diccionario fraseológico documentado del español actual: Locuciones y modismos españoles. Madrid: Aguilar-Santillana.

Venuti, L. (1995). The translator's invisibility. London \& New York: Routledge.

Xu, Z., 徐宗才 \& Ying, J. 应俊玲. (2004). Suyu cidian 俗语词典 (Diccionario de los refranes). Beijing: Shangwu yinshuguan.

Yu, G. (2016). Aproximaciones estratégicas a la traducción de los culturemas chino-español en el subtitulado televisivo. Estudio empírico-inductivo de 
un corpus paralelo (Tesis doctoral). Universidad de Salamanca, Salamanca.

Zhongguo shehui kexueyuan yuyan yanjiusuo cidian bianjishi. 中国社会科学 院语言研究所词典编辑室. (2005). 马扎. En Xiandai hanyu cidian 现代汉 语词典 (Diccionario del chino moderno) (5th edition, p. 909). Beijing: Shangwu yinshuguan.

ANEXO 1. MODELO DE LAS FICHAS.

\begin{tabular}{|c|c|}
\hline No. de la ficha & 1 \\
\hline $\begin{array}{c}\text { Categoría y sub-categoría del } \\
\text { culturema }\end{array}$ & Medio natural: topónimo \\
\hline TO & $\begin{array}{c}\text { 亲爹鬼迷心额下了关东, 一去 } \\
\text { 三年没个影... (Mo Yan, 2012, 4) }\end{array}$ \\
\hline Traducción literal del TO & $\begin{array}{c}\text { Su padre perdió el juicio y se } \\
\text { fue al Este del Paso, y durante los } \\
\text { tres años nunca ha aparecido. }\end{array}$ \\
\hline TM & $\begin{array}{c}\text { Su padre fue enviado a las } \\
\text { regiones del noreste y hace más de }\end{array}$ \\
\hline $\begin{array}{c}\text { Retrotraducción } \\
\text { tres años que no se le ha visto ni la } \\
\text { sombra. (Mo Yan, 2017,19) }\end{array}$ \\
\hline $\begin{array}{c}\text { Técnica de traducción } \\
\text { translation) del culturema }\end{array}$ & 东北地区 \\
\hline $\begin{array}{c}\text { Tendencia a extranjerización o } \\
\text { Descripción }\end{array}$ & Domesticación \\
\hline $\begin{array}{c}\text { Grado de conservación del } \\
\text { culturema } \\
\text { (de forma completa, parcial o } \\
\text { pérdida) }\end{array}$ & Parcial \\
\hline \begin{tabular}{c} 
domesticación \\
\hline
\end{tabular}
\end{tabular}

Hikma 19 (1) (2020), 95 - 115 